\title{
IMPACT OF PHYSICAL TRAINING ON SELF-CONFIDENCE
}

\author{
${ }^{1}$ Norsyahrina Abd Manaf, ${ }^{1}$ Bahaman Abu Samah, \\ ${ }^{2}$ Nobaya Ahmad, ${ }^{3}$ Jamilah Othman and ${ }^{1}$ Jeffrey Lawrence D'Silva \\ ${ }^{1}$ Institute for Social Science Studies, Universiti Putra Malaysia, Malaysia \\ ${ }^{2}$ Facultyy of Human Ecology, Universiti Putra Malaysia, Malaysia \\ ${ }^{3}$ Faculty of Educational Studies, Universiti Putra Malaysia, Malaysia
}

Received 2013-04-25, Revised 2013-06-28; Accepted 2013-08-20

ABSTRACT

As well as having a positive impact on our health, physical activity is useful for increasing self-confidence. In Malaysia, many physical programs have been organized, including the physical activities module included in Program Latihan Khidmat Negara (PLKN; the national services program). Unlike other modules, the physical activities module in PLKN is quite different due to the longer period it takes to accomplish the module. The main objective of the physical module in PLKN is to enhance the trainees' self-confidence and this study aims to discover the effectiveness of the module in this regard; i.e., how much self-confidence do trainees gain and is there any difference in their self-confidence before and after joining the module? This is a quantitative study in which a total of 362 trainees from Putra-Putri Training Camp at Alor Gajah, Malacca were selected as respondents based on multi-stage sampling. The analysis shows that the majority of trainees had a moderate level of self-confidence both pre- and post-test. However, the results demonstrate that the physical module did enhance the trainees' self-confidence based on the significant difference identified in the mean score between the pre- and post-test. It is recommended that PLKN in Malaysia should be implemented over a longer period; this would provide opportunities for new and challenging activities to be added to the program.

Keywords: Program Latihan Khidmat Negara (PLKN), Self-confidence, Physical Training

\section{INTRODUCTION}

\subsection{National Service}

National service in Malaysia is locally called Program Latihan Khidmat Negara (PLKN). The program was started in 2004 and was made compulsory to those aged 18 years and older after completing secondary school. The main objective of PLKN is to strengthen the spirits of patriotism, solidarity, volunteerism, activity, intelligence and self-confidence. PLKN has four main modules: (1) Physical Module, (2) Nation-building Module, (3) Character-building Model and (4) Community Service Module. This study only focuses on the physical training module. The main objective of the physical training module is to increase the self-confidence and resilience of the trainees. Compared to the other Corresponding Author: Norsyahrina Abd Manaf, Institute for Social Science Studies, Universiti Putra Malaysia, Malaysia

modules, the physical training module is quite long, at a duration of three months.

\subsection{Physical Training}

Physical training refers to all outdoor activities, such as jungle tracking, canoeing or kayaking, abseiling, flying fox and others, which require high resilience and physical and mental strength, as well as a spirit of cooperation and self-confidence (Ardahan, 2011; Husainay, 2004).

\subsection{Self-Confidence}

Self-confidence is a belief that one has the ability to successfully handle life and all challenges to be faced (RISDA, 2009). Usually, people who have selfconfidence are more objective, proactive and comfortable in many situations, as well as being 
happy to say anything in front of friends or groups and possess high levels of charisma (Singh and Agnihotri, 2013; Quatman et al., 2000).

\subsection{Influence of Physical Training on Self- Confidence}

Besides improving health, physical training activities such as flying fox, abseiling and jungle tracking can help people to strengthen their self-confidence and resilience particularly because, as suggested by (Yildirim et al., 2013; Colak et al., 2004; North et al., 1990) adventurous and physical activities provide opportunities for trainees to reduce and release their anxiety and depression (Oeland et al., 2010). Typically, physical training programs last a certain period of time so as to enable their trainees to learn skills relating to controlling their emotions and increasing their level of courage so as to realize their self-confidence (McLeod and Ruseski, 2013; Sherwood and Jeffery, 2000; Sonstroem and Morgan, 1989). Certainly, physical training is tough, uncomfortable and tense and involves limited time; all of these factors contribute to testing the confidence level of the trainees and those trainees with high levels of selfconfidence are most likely to be able to complete the training successfully (Brunes, 2011; Don et al., 2005). An abundance of past studies have shown a positive relationship between physical training and selfconfidence (Dembeck, 2011; Don et al., 2005; McDonald and Hodgdon, 1991).

\section{MATERIALS AND METHODS}

Based on a multi-stage sampling technique, out of 83 training camps conducted across Malaysia, Putra-Putri Training Camp at Alor Gajah, Malacca was selected for this study. A questionnaire was used to collect the data. This questionnaire was pre-tested among 30 trainees and this resulted in a Cronbach's alpha value of 0.74 , thus exceeding the threshold of 0.70 recommended by Tavakol and Dennick (2011) based on Nunally work which indicate that the instrument used for this study was reliable. A total of 15 statements were included in the questionnaire; for each statement, the respondents were given options based on a five-point Likert scale. Using factor analysis, the researchers divided the statements into three categories; (1) self-confidence during activities, (2) self-confidence through a variety of emotions and (3) self-confidence when expressing opinions. Therefore, to fulfill the objective, SPSS software was used in order to show the percentage, mean and standard deviation. To define the difference levels of the three categories and the overall level of self- confidence before and after the trainees followed the physical training, a paired sample t-test was performed.

\section{RESULTS}

A summary of the socio-demographic profile of the respondents is presented in Table 1. The respondents were divided into four groups, with the total trainees in each group being approximately equal. In terms of religion and ethnicity, the majority are Malay (61.2\%) and Islam (61.6\%). Moreover, there is an equal distribution of respondents in terms of gender, where a total of $50.3 \%$ of the respondents were male, while $49.7 \%$ were female.

The respondents were given 15 statements to measure their level of self-confidence. To fulfill the objective, they considered the statements before and after they began the physical training module. For each of the questions, the respondents were given options on a five-point Likert scale $(1=$ strongly disagree, 2 = disagree, $3=$ moderately agree, $4=$ agree, 5 = strongly agree).

The data presented in Table 2 reveal that the statement that recorded the highest mean score for the pre-test in the first category is "I took the opportunity to join a program or activity in order to improve my self-confidence" (M: 4.05) and in the post-test is "I am confident about doing abseiling" (M: 4.22). It should be noted that the lowest score for the first category for the pre- and post-test was recorded by the same statement: "I am confident when giving feedback (respond)" (pre-test M: 3.57, post-test M: 3.72).

Table 1. Socio-demographic profile of the respondents $(n=362)$

\begin{tabular}{lrr}
\hline Factor & Frequency & Percentage \\
\hline Group & 82 & \\
Alpha & 87 & 22.7 \\
Bravo & 96 & 24.0 \\
Charlie & 97 & 26.5 \\
Delta & & 26.8 \\
Ethnic & 222 & \\
Malay & 95 & 61.3 \\
Chinese & 42 & 26.2 \\
Indian & 3 & 11.6 \\
Other & & 0.8 \\
Religion & 223 & \\
Islam & 14 & 61.6 \\
Christian & 85 & 3.9 \\
Buddhism & 40 & 23.5 \\
Hindu & & 11.0 \\
Gender & 180 & \\
Female & 182 & 49.7 \\
Male & & 50.3 \\
\hline
\end{tabular}


Table 2. Self-confidence for each statement (pre- and post-tests)

\begin{tabular}{lll}
\hline & Mean & Post-test \\
\hline Statement & Pre-test & \\
\hline Self-confidence during activities & 3.75 \\
I am confident about doing abseiling & 3.95 \\
I am confident about doing activities such as canoeing/rafting & 3.60 & 4.22 \\
I have high levels of confidence and motivation & 3.70 & 4.05 \\
I am confident enough to be a great competitor in all the activities I get involved in & 3.73 \\
I took the opportunity to join a program or activity in order to improve my self-confidence & 3.57 & 3.78 \\
I am confident when giving feedback & & 3.93 \\
Self-confidence through a variety of emotions & 2.73 \\
When attending meetings or presentations, I feel anxious* & 3.01 \\
When someone gives me a difficult assignment, I & \\
get nervous and do not feel confident enoug to complete it* & 2.95 \\
I'm not confident if someone watches me work* & 2.76 \\
I feel embarrassed if I suddenly become the main focus & 3.33 \\
in a group I am involved in*I don't like to stay in areas containing a lot of people & \\
because I don't have a lot of confidence in groups* & 3.72 \\
Self-confidence when expressing opinions & 3.06 \\
I'm not embarrassed to say something to others, even if they do not like me & 3.15 \\
I'm not embarrassed to speak to others even when what I have to say is not important & 3.27 \\
I will give my suggestions before the decision is made, even in a large group discussion & 3.34 \\
I am not afraid to express my opinions and suggestions to my teammates & 3.45 \\
\hline (* is a negative statement) &
\end{tabular}

For the second category, "I don't like to stay in areas containing a lot of people because I don't have a lot of confidence in groups" (pre-test M: 3.33, post-test M: 3.21) is the highest statement for the pre-test, while the lowest for the post-test is "I feel embarrassed if I suddenly become the main focus in a group I am involved in" (pre-test M: 2.56, post-test M: 2.76). Finally, for the category "self-confidence when expressing opinions", the highest and lowest statement was the same: "I'm not embarrassed to say something to others even if they do not like me" (pre-test M: 3.06, post-test M: 3.20).

The level of overall self-confidence was computed using the mean summated score of the 15 statements. The scores were categorized into three levels, namely low, moderate and high for scores between 1-2.33, 2.34-3.66 and 3.67-5.00 respectively. Analyses indicate that the majority of respondents possess a moderate level of self-confidence at both levels: Pretest and post-test (pre-test: $73.2 \%$ and post-test: $68.0 \%$ ). However, a total of $23.8 \%$ (pre-test) and $31.2 \%$ (post-test) had a high level of self-confidence. Comparatively, only $3.0 \%$ (pre-test) and $0.8 \%$ (posttest) of the respondents had a low level of selfconfidence (Table 3 and 4). However, by using factor analysis, the three categories regarding selfconfidence were computed using the mean summated score of the six statements (first category), five statements (second category) and four statements (third category). Overall, the analysis indicates that the majority of the respondents possess a moderate level in
(1) self-confidence through a variety of emotions and (2) self-confidence when expressing opinions at both pretest and post-test levels (categories (2) pre-test: $51.7 \%$ and post-test: $68.0 \%$, (3) pre-test: $61.6 \%$ and post-test: $56.4 \%$ ) except (1) self-confidence during activities because the majority have a moderate level pre-test $(51.7 \%)$ and a high level $(62.7 \%)$ post-test.

Other results showed that all three categories found a decrease in the lower level, of which categories (1) pretest: $2.8 \%$ to post-test: $2.5 \%$, (2) pre-test: $19.9 \%$ to posttest: $19.3 \%$ and (3) pre-test: $9.9 \%$ to post-test: $6.9 \%$. However, this is in contrast with the highest level, where there was increase in (1) pre-test: $45.6 \%$ to post-test: $62.7 \%$, (2) pre-test: $16.9 \%$ to post-test: $19.1 \%$ and (3) pre-test: $28.5 \%$ to post-test: $36.7 \%$. This shows that the respondents' self-confidence changed after participating in physical training during the training period.

The findings in Table $\mathbf{5}$ show that there is a significant difference in terms of self-confidence and also that the three categories were separate, before and after the trainees followed the physical training program (overall: t: 425, p: .000, (1) t: 5.17, p: .000, (2) t: 1.89, p: .030 and (3) t: 3.74 , p: .000). This finding shows that trainees who followed the physical training program during PLKN successfully improved their selfconfidence. These results are not surprising, as they are in line with a study conducted by (Debate et al., 2009; Faulkner et al., 2007; Sonstroem, 1998) who claimed that physical training can help to improve confidence, motivation and courage. 
Table 3. Level of self-confidence (pre-test)

\begin{tabular}{|c|c|c|c|c|}
\hline Level & Frequency & Percentage & Mean & S.D \\
\hline \multicolumn{5}{|c|}{ Self-confidence during activities } \\
\hline Low (1.00-2.33) & 10 & 2.8 & 3.72 & 0.63 \\
\hline \multicolumn{5}{|l|}{ Moderate (2.34-3.66) } \\
\hline High (3.67-5.00) & 165 & 45.6 & & \\
\hline \multicolumn{5}{|c|}{ Self-confidence through a variety of emotions } \\
\hline Low (1.00-2.33) & 72 & 19.9 & 2.92 & 0.83 \\
\hline Moderate (2.34-3.66) & 229 & 63.3 & & \\
\hline High $(3.67-5.00)$ & 61 & 16.9 & & \\
\hline \multicolumn{5}{|c|}{ Self-confidence when expressing opinions } \\
\hline Low (1.00-2.33) & 36 & 9.9 & 3.28 & 0.71 \\
\hline Moderate (2.34-3.66) & 223 & 61.6 & & \\
\hline High (3.67-5.00) & 103 & 28.5 & & \\
\hline \multicolumn{5}{|l|}{ Overall } \\
\hline Low (1.00-2.33) & 11 & 3.0 & 3.35 & 0.58 \\
\hline Moderate (2.34-3.66) & 265 & 73.2 & & \\
\hline High (3.67-5.00) & 86 & 23.8 & & \\
\hline
\end{tabular}

Table 4. Level of self-confidence (post-test)

\begin{tabular}{|c|c|c|c|c|}
\hline Level & Frequency & Percentage & Mean & S.D \\
\hline \multicolumn{5}{|c|}{ Self-confidence during activities } \\
\hline Low (1.00-2.33) & 9 & 2.5 & 3.90 & 0.68 \\
\hline Moderate (2.34-3.66) & 126 & 34.8 & & \\
\hline High (3.67-5.00) & 227 & 62.7 & & \\
\hline \multicolumn{5}{|c|}{ Self-confidence through a variety of emotions } \\
\hline Low (1.00-2.33) & 70 & 19.3 & 3.00 & 0.81 \\
\hline Moderate (2.34-3.66) & 223 & 61.6 & & \\
\hline High (3.67-5.00) & 69 & 19.1 & & \\
\hline \multicolumn{5}{|c|}{ Self-confidence when expressing opinions } \\
\hline Low (1.00-2.33) & 25 & 6.9 & 3.44 & 0.72 \\
\hline Moderate (2.34-3.66) & 204 & 56.4 & & \\
\hline High (3.67-5.00) & 133 & 36.7 & & \\
\hline \multicolumn{5}{|l|}{ Overall } \\
\hline Low (1.00-2.33) & 3 & 0.8 & 3.48 & 0.53 \\
\hline Moderate (2.34-3.66) & 246 & 68.0 & & \\
\hline High (3.67-5.00) & 113 & 31.2 & & \\
\hline
\end{tabular}

Table 5. Comparison of self-confidence

\begin{tabular}{|c|c|c|c|c|}
\hline & Mean & S.D & $\mathrm{t}$ & $\mathrm{p}$ \\
\hline \multicolumn{5}{|c|}{ Self-confidence during activities } \\
\hline Pre-test & 3.72 & 0.63 & \multirow[t]{2}{*}{5.17} & \multirow[t]{2}{*}{00.000} \\
\hline Post-test & 3.90 & 0.68 & & \\
\hline \multicolumn{5}{|c|}{ Self-confidence through a variety of emotions } \\
\hline Pre-test & 2.92 & 0.83 & \multirow[t]{2}{*}{1.89} & \multirow[t]{2}{*}{0.0300} \\
\hline Post-test & 3.00 & 0.81 & & \\
\hline \multicolumn{5}{|c|}{ Self-confidence when expressing opinions } \\
\hline Pre-test & 3.28 & 0.71 & \multirow[t]{2}{*}{3.74} & \multirow[t]{2}{*}{0.0000} \\
\hline Post-test & 3.44 & 0.72 & & \\
\hline \multicolumn{5}{|l|}{ Overall } \\
\hline Pre-test & 3.35 & 0.58 & \multirow[t]{2}{*}{4.29} & \multirow[t]{2}{*}{0.0000} \\
\hline Post-test & 3.48 & 0.53 & & \\
\hline
\end{tabular}




\section{DISCUSSION}

The results obtained here show that physical training during PLKN improves trainees' self-confidence. Based on Table 3, the analysis shows that a number of trainees exhibited confidence differences at the three levels (low, moderate and high) between the pre-test and post-test. For example, for the first categories, we can see that the lower and moderate level decreased, while the highest level increased. Through interviews during the data collection (pre-test) stage, the researcher found that a large number of trainees do not take part in activities such as flying fox and abseiling because they have less of confidence. However, after three months' participation in the program, the number of trainees who had the confidence to join in with these activities increased (pre-test: 165, post-test: 227). This increase can be explained by a number of factors. First, activities such as jungle tracking, flying fox and abseiling are able to build skills in leadership, mental resilience and confidence. Although some of them are active in school, nonetheless they will not able to gain a higher level of self-confidence as they gain through the national services program. Typically, activities conducted in school such as camping and marching are only conducted periodically; unlike continuous programs such as PLKN, this limited activity has a minimum impact on their level of self-confidence. Non-active students in school will get an opportunity to become more physical by taking part in PLKN, which offers them new experiences and, at the same time, improves their levels of self-confidence. Consequently, PLKN is considered a continuous program which has the ability to create high levels of self-confidence among young people for the future and this is in parallel with the philosophy of national education. As a conclusion, physical training in PLKN can develop more disciplined people, who have a higher level of patriotism and self-confidence, as well as loyalty to the country and are prepared to face any challenges and to foster cooperation and unity in the country. This formation is consistent with the philosophical tenets of the country, which were introduced in 1970 and further enhanced in the Vision 2020, which was intended to provide direction for the country's development. Based on this finding, it is recommended that national service in Malaysia should be implemented for a longer period; the duration of physical training is suggested to be increased, which will provide opportunities for new and challenging activities to be added. In turn, this could lead to significant improvements in term of trainees' self-confidence. In addition, more trainees should be selected to participate in PLKN; this will offer them chances to learn something from the activities in question. Moreover, it will allow the government to combat social problems among youth in Malaysia.

\section{CONCLUSION}

Based on the analysis done, it can be concluded that physical training in national service provides an opportunity for trainees to improve their levels of selfconfidence. Overall, the majority of trainees have a moderate level of self-confidence. To ensure that the improvement from the program is significant in the future, it is suggested that organizers improve all aspects of the module and facilities and provide experienced trainers so that the trainees can get more benefits from the overall physical training.

\section{REFERENCES}

Ardahan, F., 2011. The Profile of the Turkish mountaineer and rock climbers: The reasons and carriedbenefits for attending outdoor sports and life satisfaction level. Akdeniz University.

Brunes, A., 2011. The association between physical activity, mental health and personality: The HUNT study. Norwegian University of Science and Technology.

Colak, T., B. Bamac, M. Aydin, B, Meric and A. Ozbek, 2004. Physical fitness levels of blind and visually impaired goalball team players. Isokine Exerc. Sci., 12: $247-52$.

Debate, R.D., K.P. Gabriel, M. Zwald, J. Huberty and Y. Zhang, 2009. Changes in psychosocial factors and physical activity frequency among third- to eighthgrade girls who participated in a developmentally focused youth sport program: A preliminary study. J. School Health, 79: 474-484. DOI: 10.1111/j.17461561.2009.00437.x

Dembeck, K., 2011. Physical Activity and Self-Esteem in Females During Late Adolescence. MSc Thesis, University of North Florida.

Don, Y., A.S. Shari and M.N. Ajis, 2005. Penilaian Program Latihan Khidmat Negara (PLKN) melalui gagasan latihan fizikal. Universiti Utara Malaysia.

Faulkner, G.E.J., E.M. Adlaf, H.M. Irving, K.R. Allison and J.J.M. Dwyer et al., 2007. The relationship between vigorous physical activity and juvenile delinquency: A mediating role for self-esteem? J. Behav. Med., 30: 155-163. PMID: 17268877 
Husainay, H., 2004. Malaysia Physical Training Manual. 1st Edn., Institut Kepimpinan Wawasan, Selangor Darul Ehsan.

McDonald, D.G. and J.A. Hodgdon, 1991. The Psychological Effects of Aerobic Fitness Training: Research and Theory. 1st Edn., Springer-Verlag, New York, ISBN-10: 0387976035, pp: 224.

McLeod, L. and J.E. Ruseski, 2013. Longitudial Relationship between Participation in Physical Activity and Health. University of Alberta.

North, T.C., P. McCullagh and Z.V. Tran, 1990. Effect of exercise on depression. Exercise Sports Sci. Rev., 18: 379-415. PMID: 2141567

Oeland, A.E., U. Laessoe, A.V. Olesen and P. MunkJorgensen, 2010. Impact of exercise on patients with depression and anxiety. Nord. J. Psychiatry, 64: 210217. PMID: 20100135

Quatman, T., E. Sokolik and K. Smith, 2000. Adolescent perception of peer success: A gendered perspective over time. Sex Roles, 43: 61-84. DOI: 10.1023/A:1007039712348
RISDA, 2009. Pengertian, Kepentingan and Keajaiban Keyakinan Diri. RISDA, Malayisa.

Sherwood, N. and R. Jeffery, 2000. The behavioral determinants of exercise: Implications for physical activity interventions. Annual Rev. Nutrit., 20: 2144. PMID: 10940325

Singh, R. and A. Agnihotri, 2013. Mental health of secondary school students in relation to self confidence.

Sonstroem, R.J. and W.P. Morgan, 1989. Exercise and self-esteem: Rationale and model. Med. Sci. Sports Exerc., 21: 329-337. PMID: 2659918

Sonstroem, R.J., 1998. Physical self-concept: Assessment and external validity. Exerc. Sport Sci. Rev., 26: 133-164. PMID: 9696988

Tavakol, M. and R. Dennick, 2011. Making sense of Cronbach's alpha. Int. J. Med. Educ., 2011: 53-55.

Yildirim, S., R. Yuksel, S. Doganay, M. Gul and F. Bingol et al., 2013. The benefits of regular physical activity on hearing in visually impaired adolescents. Eur. J. Basic Med. Sci., 3: 17-21. 